\title{
CrystEngComm
}

\section{Synthesis, structure and non-linear optical properties of L-argininium perrhenate crystal $\dagger$}

\author{
Dmitry Isakov, ${ }^{a}$ Etelvina de Matos Gomes, ${ }^{* a}$ Michael Scott Belsley, ${ }^{a}$ Vitor Hugo Rodrigues ${ }^{b}$ \\ and Maria Margarida Ramalho Costa ${ }^{b}$
}

\author{
Received 9th December 2011, Accepted 16th February 2012 \\ DOI: 10.1039/c2ce06652a
}

\begin{abstract}
A new hybrid organic-inorganic non-linear optical crystalline material, L-argininium perrhenate has been synthesized. The crystal belongs to $P 2_{1} 2_{1} 2_{1}$ space group, has a good optical quality and high transmission in the visible and near infra-red spectral regions. L-argininium perrhenate has high birefringence and is more than four times as efficient as KDP in second harmonic generation, making it a potentially attractive material for non-linear optical applications.
\end{abstract}

\section{Introduction}

The synthesis of novel non-linear optical materials capable of efficient second harmonic generation or electro-optic modulation has been an exceedingly active area of research in the last two decades because of its importance in providing the key functions of frequency shifting, optical modulation, optical switching and optical memory for technologies in areas such as telecommunications, signal processing, and optical interconnections. ${ }^{1-5}$

One approach to obtain new non-linear optical crystalline materials with enhanced properties, is the supramolecular engineering of hybrids built from organic-inorganic complexes in which the high optical non-linearity of a purely organic compound is combined with the favourable mechanical and thermal properties of an inorganic material. ${ }^{6-10}$ Compared to pure organic or inorganic materials, hybrid organic-inorganic crystalline materials are relatively easy to grow and possess a large degree of chemical flexibility while accommodating a variety of different structural designs. In particular, hydrogen bonds may be used to construct molecular building blocks with structures that can be controlled in both one and two dimensions, giving rise to crystalline materials with large non-linear and electro-optic optical responses. ${ }^{11-17}$

A wide range of chemical and physical approaches have been developed to achieve non-centrosymmetric assemblies and optical second harmonic generation (SHG) in hybrid organic-inorganic bulk materials. ${ }^{18-23}$ Amino acids are interesting molecules for nonlinear optical (NLO) applications as they contain a proton donor, carboxyl acid (COO) group, and a proton acceptor, amino $\left(\mathrm{NH}_{2}\right)$ group, and all of them are chiral, except for glycine, which assures

${ }^{a}$ CFUM, Departamento de Física, Universidade do Minho, 4710-059 Braga, Portugal. E-mail: emg@fisica.uminho.pt; Fax: +351 253 604061; Tel: +351253604061

${ }^{b}$ CEMDRX, Departamento de Física, FCT, Universidade de Coimbra, 3004-516 Coimbra, Portugal

$\dagger$ CCDC reference number 857125. For crystallographic data in CIF or other electronic format see DOI: 10.1039/c2ce06652a crystalline non-centrosymmetry. L-arginine is an essential chiral amino acid that occurs widely in biological substances. It forms a number of hydrogen bonded crystalline salts with different acids, such as phosphoric, fluoridic, chloridic, formic and acetic acids, some of them with strong NLO properties. ${ }^{24-28}$

Among these L-arginine phosphate monohydrate (LAP) ${ }^{\mathbf{2 9 , 3 0}}$ is perhaps the best known and technologically important hybrid organic-inorganic crystalline non-linear material. It has a low level of hygroscopicity, is transparent in the visible and infra-red $(220-1950 \mathrm{~nm})$, is chemically stable and is transparent. This covers the wavelength range as the widely used inorganic compound potassium hydrogen phosphate (KDP). However, LAP displays a three times greater non-linearity and also three times higher damage threshold.

Recently a new semi-organic hydrogen-bonded ferroelectric crystal, 1,4-diazabicyclo[2.2.2] octane perrhenate $\left(\right.$ dabcoHReO$\left._{4}\right)$ exhibiting exceptional dielectric properties that result from the unique structure where all the bistable $\mathrm{NH} \cdots \mathrm{N}$ hydrogen bonds are parallel and directed in the same sense, was reported. ${ }^{31}$

Aiming to extend the number of LAP analogs with potential ferroelectric and non-linear optical properties, we have attempted the synthesis of L-arginine with perrhenic acid and a new non-linear optical crystalline non-linear material was obtained, L-arginium perrhenate $\left(\mathrm{C}_{6} \mathrm{H}_{14} \mathrm{~N}_{4} \mathrm{O}_{2} \mathrm{HReO}_{4}\right)$, having a non-linearity similar to LAP. Here we report the synthesis, structural and optical characterization of this new crystalline material which represents another step in this quest to discover new high performing second harmonic generating crystals within the family of L-arginine salts, extending the number of LAP analogs.

\section{Experimental}

\subsection{Synthesis}

The crystals of L-argininium perrhenate (hereafter LARe) were synthesized by dissolving stoichiometric amounts of L-arginine 
(Sigma-Aldrich 98,5\%) and perrhenic acid (Sigma-Aldrich, 65-70 wt.\%) in distilled water at $40{ }^{\circ} \mathrm{C}$. Polycrystalline LARe was obtained by evaporation of the filtered solution at room temperature. The crystals were further purified by a re-crystallization process in deionised water. Small plate-like crystals with dimensions as large as $5 \times 1 \times 10 \mathrm{~mm}^{3}$ were obtained from the saturated aqueous solutions after several weeks at room temperature. A plane-parallel LARe crystal sample plate of $1 \mathrm{~mm}$ thicknesses with the main face parallel to [001] was grinded, fine polished by Struers's synthetic short nap (MD-Nap) with diamond grain size smaller than $1 \mu \mathrm{m}$ and used for further characterization. The LARe single crystals have good chemical stability and can be stored at room temperature with no degradation for several months, even with a relative humidity of $40-50 \%$.

Thermal analysis on a Perkin Elmer System 4 thermal analysis controller showed no phase transition from $80 \mathrm{~K}$ until melting at $518 \mathrm{~K}\left(248^{\circ} \mathrm{C}\right)$.

\subsection{Structure determination}

A small crystal was selected from the synthesized material and used for data collection at room temperature on a Bruker APEXII diffractometer with Mo-K $\alpha(\lambda=0.71073 \AA)$. Cell refinement and data reduction were performed using the algorithms implemented in SAINT Bruker, v. 7.06a (Bruker AXS Inc. 2003, Madison, Wisconsin, USA). The structure was solved by direct methods using SHELXS-97 and the resulting model refined with SHELXL. ${ }^{32}$ All $\mathrm{H}$ atoms were placed at idealised positions and refined as riding $\left[\mathrm{C}-\mathrm{H}=0.93 \AA\right.$ (aromatic C), $0.97 \AA\left(\mathrm{CH}_{2}\right)$ and $\left.0.96 \AA\left(\mathrm{CH}_{3}\right), U_{\text {iso }}(\mathrm{H})=1.2 U_{\text {eq }}(\mathrm{C})\right]$. Examination of the crystal structure with PLATON ${ }^{33}$ showed that there are no solventaccessible voids in the crystal lattice.

\subsection{Linear optical and non-linear optical characterization}

Optical transmission data was taken at room temperature between 200 and $2000 \mathrm{~nm}$, on a flat polished crystal sample of about $1 \mathrm{~mm}$ in thickness, using a Shimadzu UV-3101PC UV-VIS-NIR spectrophotometer. The refractive indices for 532 and $1064 \mathrm{~nm}$ wavelengths, were measured using a Mach-Zehnder interferometer setup by rotating appropriately oriented crystal plates in one arm and counting the resulting number of interference fringes. ${ }^{34,35}$ Because of the plate-like morphology of LARe crystal $(z>x>y)$, the $n_{2}$ refractive index measurement was not possible due to small $x y$ area $\left(\sim 2 \mathrm{~mm}^{2}\right)$ and consequently it was calculated from the phase matching SHG measurements.

The second-order non-linear optical susceptibility was evaluated using the Maker-fringe method. ${ }^{36}$ A Q-switched Nd:YAG laser with $1064 \mathrm{~nm}$ wavelength, $10 \mathrm{~Hz}$ repetition rate and $10 \mathrm{~nm}$ pulse width was used to emit the fundamental beam. A (110) plate of KDP has been used as a reference sample.

\section{Results and discussion}

\subsection{Crystal structure}

Crystal data and structure refinement of the title compound can be found in Table 1. The L-argininium cation (LA) (Fig. 1) contains three nearly planar sub-groups, a feature that is common to all LA cations in the 71 crystal structures reported to the CSD. ${ }^{37}$ Those subgroups consist of a zig-zag chain extending from $\mathrm{C} 2$ to the $\mathrm{N} 2$ of the guanidyl group, a carboxylate group and a guanidyl side chain. The conformation of LA is described by a number of torsional angles defined by the IUPACIUB Commission on Biochemical Nomenclature (1975), namely $\varphi^{1}=\mathrm{O} 5-\mathrm{C} 1-\mathrm{C} 2-\mathrm{N} 1, \varphi^{2}=\mathrm{O} 6-\mathrm{C} 1-\mathrm{C} 2-\mathrm{N} 1, \chi^{1}=\mathrm{N} 1-\mathrm{C} 2-\mathrm{C} 3-\mathrm{C} 4$, $\chi^{2}=\mathrm{C} 2-\mathrm{C} 3-\mathrm{C} 4-\mathrm{C} 5, \chi^{3}=\mathrm{C} 3-\mathrm{C} 4-\mathrm{C} 5-\mathrm{N} 2, \chi^{4}=\mathrm{C} 4-\mathrm{C} 5-\mathrm{N} 2-\mathrm{C} 6$, $\chi^{51}=\mathrm{C} 5-\mathrm{N} 2-\mathrm{C} 6-\mathrm{N} 3$ and $\chi^{52}=\mathrm{C} 5-\mathrm{N} 2-\mathrm{C} 6-\mathrm{N} 4$. In 1967, when only a small number of crystal structures containing the LA cation were known, it was proposed that $\chi^{2}$ should be close to one of three possible values, scilicet $60^{\circ}, 180^{\circ}$ or $-60^{\circ} .{ }^{38}$ The LA structures reported up-to-date in the CSD still support this empirical rule and the three possible corresponding positions of the $\gamma$-C, namely gauche both to amino and carboxyl $(+\mathrm{sc})$, trans to amino (ap) and trans to carboxyl ( $-\mathrm{sc}$ ), are found to be nearly equally probable ${ }^{37}$ amongst the reported LA crystal structures. In the LARe compound $\gamma-\mathrm{C}(\mathrm{C} 4)$ is trans to the amino (ap) with $\chi^{1}=-160.9(5)^{\circ}$. All the relevant torsion angles are reported in the Table 2.

The $\mathrm{C}-\mathrm{O}$ and $\mathrm{C}-\mathrm{N}$ bond lengths are nearly equal indicating that carboxyl, amino and guanidyl groups are fully ionized. The $\mathrm{Re}-\mathrm{O}$ bond lengths can be grouped in two pairs, the two short distances corresponding to the higher electron densities; this is further confirmed by a larger value of the corresponding $\mathrm{O}-\mathrm{Re}-$ $\mathrm{O}$ angle, and is consistent with a slight distortion from the ideal tetrahedral geometry. Thus, charge neutrality is consistent only with an ionized amino group. Three idealized amino $\mathrm{H}$ atom positions were therefore calculated, maximizing the electron density, and a subsequent rigid group refinement of the calculated coordinates was carried out (allowing the rotation around the $\mathrm{C} 5-\mathrm{N} 2$ bond). Furthermore the $\mathrm{C} 6-\mathrm{N} 3$ and $\mathrm{C} 6-\mathrm{N} 4$ bond lengths indicate an electronic charge delocalization (conjugated bonds), consistent with the planarity of the guanidyl group. The intermolecular structure of the title compound consists of a three-dimensional hydrogen bonded network interconnecting the anions and the cations, shown in Fig. 2. In the latter network every amino or guanidyl $\mathrm{H}$ atom is donated to an $\mathrm{O}$ atom of either the carboxyl group of the cation or to one of the $\mathrm{O}$ atoms of the anion, e.g., hydrogen bonding is present to its maximum possible extent. Details of the hydrogen bonds are given in the Table 3.

The three-dimensional (3D) network can be pictured as a stacking of 2D sheets of hydrogen bonded LA cations, parallel to the $a c$ plane (Fig. 3). Further hydrogen bonding between neighboring sheets, which are closely packed and are mirror images of each other, and between the sheets and the intercalated anions completes the overall 3D network.

It is interesting to note that in LAP, the crystal structure consists of alternate layers of LA molecules and phosphate groups stacked together along a crystallographic axis and held together by hydrogen bonds. Here LA molecules and the perrhenate ions do not form stacked alternate layers.

\subsection{Optical characterization}

The optical transmission spectra of LARe is shown in Fig. 4. The absorption edge is located at $240 \mathrm{~nm}$ and the crystals have a broad transparency with a transmission greater than $80 \%$ for wavelengths from $400 \mathrm{~nm}$ up to $1400 \mathrm{~nm}$. This makes LARe 
Table 1 Crystal data and structure refinement

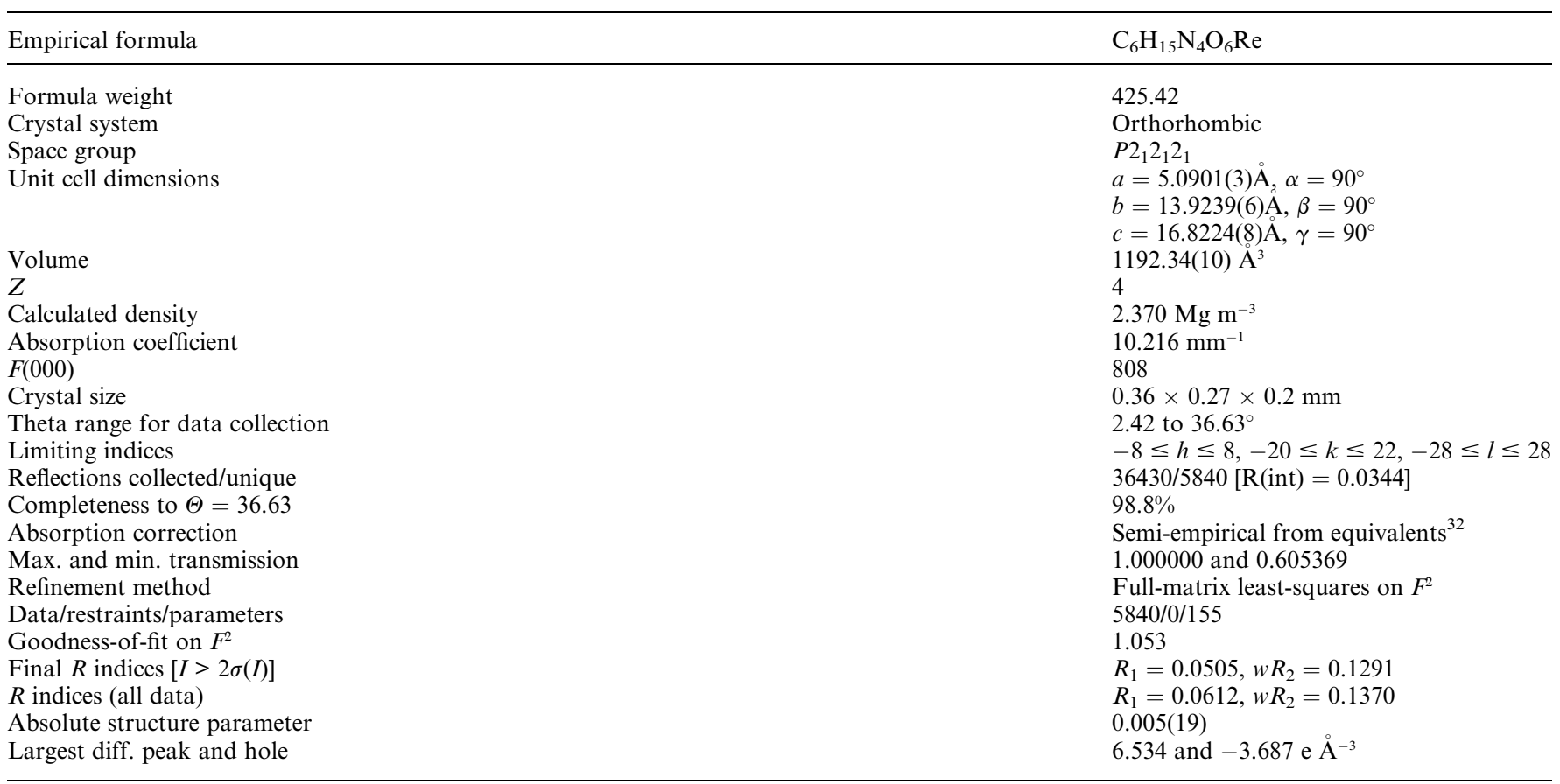

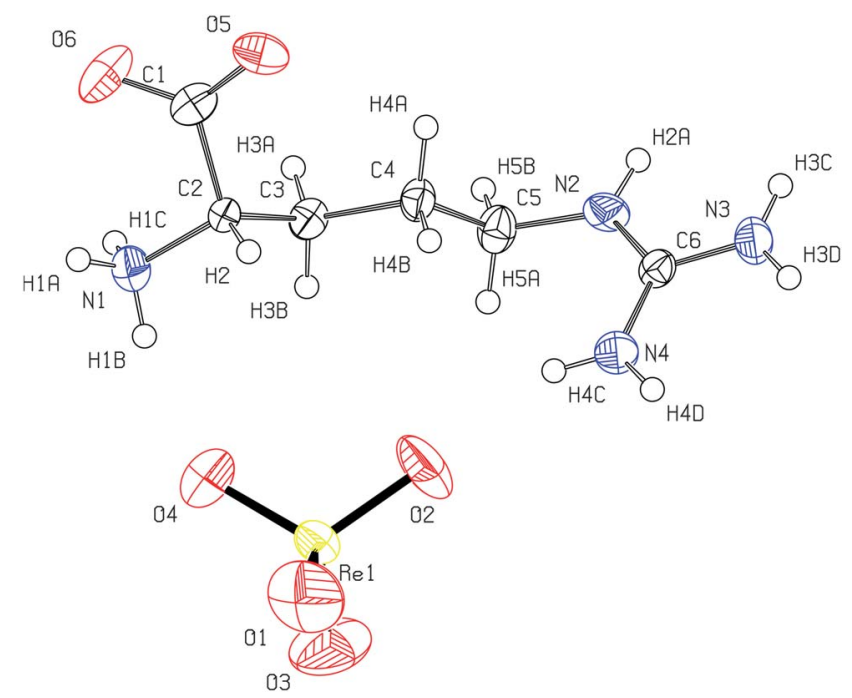

Fig. 1 Ortep ${ }^{39}$ drawing of LA cation and perrhenate anion of the title compound, to elucidate the numbering scheme. Vibrational ellipsoids are drawn at a $50 \%$ level.

crystals potentially interesting for applications that require blue green light as well as second harmonic generation processes at IR fundamental laser beam.

The indices of refraction measured for 532 and $1064 \mathrm{~nm}$ wavelengths are presented in Table 4 . In the orthorhombic crystallographic system the principal dielectric axes $n_{1}, n_{2}$ and $n_{3}$ coincide with the crystallographic axes $x, y$ and $z$ respectively. Using this geometry, plane polarized light parallel to the crystallographic axis and specific crystal orientation was used in the measurements. Due to the thin plate-like LARe morphology only two refractive indices, $n_{1}$ and $n_{3}$, were measured accurately. The $n_{2}$ index was obtained from the phase matching SHG
Table 2 Torsion angles defined by the IUPAC-IUB

\begin{tabular}{ll}
\hline Conformation & \\
\hline $\mathrm{O}(6)-\mathrm{C}(1)-\mathrm{C}(2)-\mathrm{N}(1)$ & $-8.1(8)$ \\
$\mathrm{O}(5)-\mathrm{C}(1)-\mathrm{C}(2)-\mathrm{N}(1)$ & $171.6(6)$ \\
$\mathrm{O}(6)-\mathrm{C}(1)-\mathrm{C}(2)-\mathrm{C}(3)$ & $112.6(7)$ \\
$\mathrm{O}(5)-\mathrm{C}(1)-\mathrm{C}(2)-\mathrm{C}(3)$ & $-67.6(7)$ \\
$\mathrm{N}(1)-\mathrm{C}(2)-\mathrm{C}(3)-\mathrm{C}(4)$ & $-160.9(5)$ \\
$\mathrm{C}(1)-\mathrm{C}(2)-\mathrm{C}(3)-\mathrm{C}(4)$ & $78.4(6)$ \\
$\mathrm{C}(2)-\mathrm{C}(3)-\mathrm{C}(4)-\mathrm{C}(5)$ & $167.3(5)$ \\
$\mathrm{C}(3)-\mathrm{C}(4)-\mathrm{C}(5)-\mathrm{N}(2)$ & $179.3(5)$ \\
$\mathrm{C}(4)-\mathrm{C}(5)-\mathrm{N}(2)-\mathrm{C}(6)$ & $74.6(8)$ \\
$\mathrm{C}(5)-\mathrm{N}(2)-\mathrm{C}(6)-\mathrm{N}(4)$ & $2.2(10)$ \\
$\mathrm{C}(5)-\mathrm{N}(2)-\mathrm{C}(6)-\mathrm{N}(3)$ & $-176.4(6)$ \\
\end{tabular}

measurements. If the propagation direction of the incident fundamental beam is in the $x y$-plane and polarization of the second harmonic wave is parallel to $c$-axis, then the dispersion of the indexes of refraction can be expressed as:

$$
\sin ^{2} \Theta_{\mathrm{m}}=\frac{n_{3}^{-2}(2 \omega)-n_{1}^{-2}(\omega)}{n_{2}^{-2}(\omega)-n_{1}^{-2}(\omega)},
$$

where $\Theta_{\mathrm{m}}$ is the observed phase matching angle between the $b$ and $c$ axis $\left(\Theta_{\mathrm{m}}=71^{\circ}\right)$, and is measured with respect to the $b$ axis. The good transparency in the region between 400 and 1400 $\mathrm{nm}$ together with a large birefringence make the LARe crystal as a promising material for SHG in the visible and near UV region.

The non-linear optical susceptibility in LARe was obtained using the Maker-fringe method by rotation of an oriented planeparallel crystal with the appropriate fundamental and second harmonic polarization. From the resulting interference patterns of the generated second harmonic signal the relative magnitudes of NLO coefficients can be determined. 


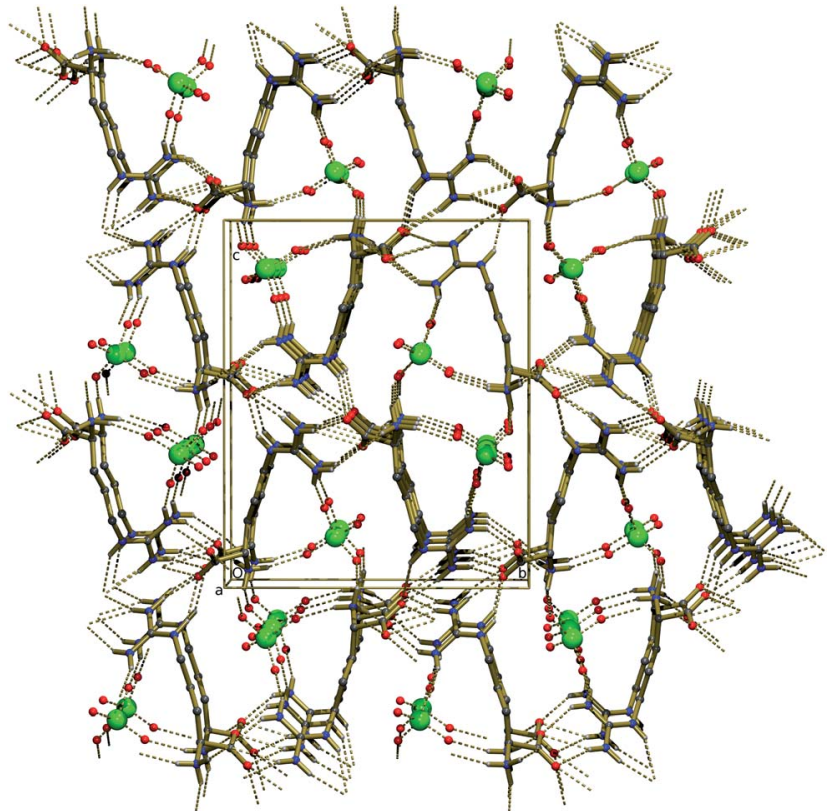

Fig. 2 Three-dimensional hydrogen bonded network depicting intermolecular binding of LA and perrhenate ions.

Table 3 Hydrogen bonds ${ }^{a}$

\begin{tabular}{lllll}
\hline $\mathrm{D}-\mathrm{H} \cdots \mathrm{A}$ & $d(\mathrm{D}-\mathrm{H})$ & $d(\mathrm{H} \cdots \mathrm{A})$ & $d(\mathrm{D} \cdots \mathrm{A})$ & $<\mathrm{DHA}$ \\
\hline $\mathrm{N}(1)-\mathrm{H}(1 \mathrm{~A}) \cdots \mathrm{O}(1)^{\dagger}$ & 0.89 & 2.44 & $2.774(10)$ & 102.6 \\
$\mathrm{~N}(1)-\mathrm{H}(1 \mathrm{~B}) \cdots \mathrm{O}(4)$ & 0.89 & 2.03 & $2.900(11)$ & 166.8 \\
$\mathrm{~N}(1)-\mathrm{H}(1 \mathrm{C}) \cdots \mathrm{O}(5)^{\ddagger}$ & 0.89 & 1.86 & $2.737(8)$ & 169.3 \\
$\mathrm{~N}(2)-\mathrm{H}(2 \mathrm{~A}) \cdots \mathrm{O}(6)^{\S}$ & 0.86 & 2.28 & $3.039(8)$ & 147.8 \\
$\mathrm{~N}(3)-\mathrm{H}(3 \mathrm{C}) \cdots \mathrm{O}(6)^{\S}$ & 0.86 & 2.05 & $2.842(8)$ & 152.5 \\
$\mathrm{~N}(3)-\mathrm{H}(3 \mathrm{D}) \cdots \mathrm{O}(5)^{\uparrow}$ & 0.86 & 2.35 & $3.082(8)$ & 143.8 \\
$\mathrm{~N}(3)-\mathrm{H}(3 \mathrm{D}) \cdots \mathrm{O}(6)^{\uparrow}$ & 0.86 & 2.40 & $3.225(10)$ & 160.4 \\
$\mathrm{~N}(4)-\mathrm{H}(4 \mathrm{C}) \cdots \mathrm{O}(2)$ & 0.86 & 2.17 & $2.994(10)$ & 159.6 \\
$\mathrm{~N}(4)-\mathrm{H}(4 \mathrm{D}) \cdots \mathrm{O}(5)^{\uparrow}$ & 0.86 & 2.18 & $2.959(8)$ & 150.4 \\
$\mathrm{C}(5)-\mathrm{H}(5 \mathrm{~A}) \cdots \mathrm{O}(2)$ & 0.97 & 2.57 & $3.347(10)$ & 137.1
\end{tabular}

${ }^{a}$ Symmetry transformations used to generate equivalent atoms: ${ }^{\dagger} x-1 / 2$, $-y+1 / 2,-z+2 ;{ }^{\ddagger} x-1, y, z ;{ }^{\S}-x+3 / 2,-y+1, z-1 / 2 ;{ }^{\uparrow}-x+2, y-1 / 2$, $-z+3 / 2$.

For the orthorombic 222 point group, $d_{14}, d_{25}$ and $d_{36}$ are the only non-zero coefficients of the SHG tensor. Applying different light polarization and assuming that the polarizations of the second harmonic light is $P_{1}^{(2 \omega)}=d_{14} E_{2} E_{3}$ and $P_{3}^{(2 \omega)}=d_{36} E_{1} E_{2}$, the $d_{14}$ and $d_{36}$ coefficients have been obtained. Again, due to the thinness of the LARe $b$-face, the determination of $d_{25}$ was not feasible. For quantitative measurements of the NLO coefficients, the relative intensities of the Maker-fringe envelopes for LARe were normalized by those obtained from a KDP crystal under identical conditions. The measurements yields $d_{14}^{\text {(LARe) }}=1.1 \times$ $d_{36}^{(\mathrm{KDP})}$ and $d_{36}^{(\mathrm{LARe})}=4.6 \times d_{36}^{(\mathrm{KDP})}$, indicating that LARe is a promising material for efficient second harmonic generation.

The laser damage threshold is an important characteristic for practical usage of non-linear crystals. The induced surface breakdown in LARe have been performed in a multiple-shots mode on the polished (001) crystal plate using a focused (about $0.1 \mathrm{~mm}$ beam diameter) Q-switched Nd:YAG pulse laser with

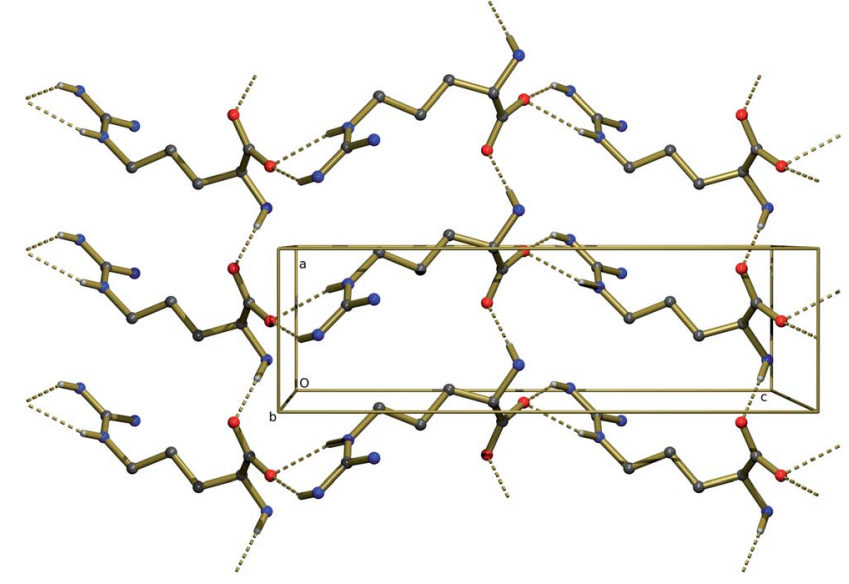

Fig. 3 Two-dimensional network of LA cations parallel to the $a c$ plane. Chains running vertically (along $a$ ) and horizontally (along $c$ ) intersect to give rise to the shown network.

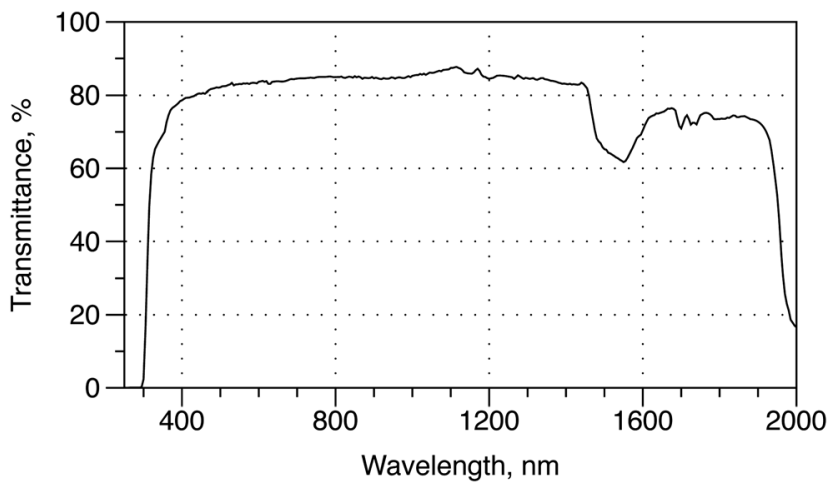

Fig. 4 Optical transmission spectra of LARe crystal.

Table 4 The principal indices of refraction in $\mathrm{LAHReO}_{4}$ crystal

\begin{tabular}{llll}
\hline $\begin{array}{l}\text { Wavelength } \\
(\mathrm{nm})\end{array}$ & $\begin{array}{l}\text { Wavelength } \\
(\mathrm{nm})\end{array}$ & $\begin{array}{l}\text { Wavelength } \\
(\mathrm{nm})\end{array}$ & $\begin{array}{l}\text { Wavelength } \\
(\mathrm{nm})\end{array}$ \\
\hline 532 & $1.5252 \pm 0.0045$ & & $1.4617 \pm 0.0043$ \\
1064 & $1.4868 \pm 0.0039$ & $1.4588 \pm 0.0163$ & $1.4341 \pm 0.0048$ \\
\hline
\end{tabular}

$7 \mathrm{~ns}$ pulse width and $10 \mathrm{~Hz}$ repetition rate. The damage have been observed by the formation of a spark accompanied by abrupt decease of the SHG intensity. The power level of the Nd:YAG laser at which a sharp reduction in the SHG intensity was observed to be $1.26 \mathrm{GW} \mathrm{cm}_{2}^{-1}$ for $1064 \mathrm{~nm} \mathrm{Nd:YAG} \mathrm{laser}$ radiation. This can be taken as indicative of the damage threshold values and is the same order of magnitude as urea.

\section{Conclusions}

A new L-arginine hybrid organic-inorganic crystalline material has been synthesized and its structure solved. The crystal structure displays a three dimensional hydrogen bonded network depicting intramolecular binding of L-arginine and perrhenate ions showing that the amino acid entities are strongly anchored onto the inorganic entities. 
The crystals of LARe are transparent in the visible and near infrared optical spectrum, have high birefringence, a high damage threshold and a second harmonic generation efficiency four times greater than KDP, which makes these new crystals potentially interesting non-linear optical materials for optical applications, extending the number of LAP amino-acid analogs.

\section{Acknowledgements}

This work was financially supported by the European Regional Development Fund (ERDF) through Programa Operacional Factores de Competitividade (COMPETE: FCOMP-01-0124FEDER-014628) and the Portugal Fundação para a Ciência e Tecnologia (PTDC/CTM-NAN/114269/2009, PTDC/CTM/ 105597/2008 and Pest-C/FIS/UI0036/2011).

\section{References}

1 M. D. Aggarwal, W. S. Wang, K. Bhat, B. G. Penn and D. O. Frazier, Handbook of advanced electronic materials and devices, Academic Press, San Diego, CA, 2001.

2 P. N. Prasad and D. J. Williams, Introduction to non-linear optical effects in organic molecules and polymers, Wiley, New York, 1991.

3 J. Zyss and D. S. Chemla, Nonlinear optical properties of organic molecules and crystals, Academic Press, Orlando, FL, USA, 1987.

4 H. S. Nalwa and S. Miyata, Nonlinear Optics of Organic Molecules and Polymers, CRC Press, Boca Raton, FL, USA, 1997.

5 D. F. Eaton, Science, 1991, 253, 281-287.

6 O. R. Evans and W. B. Lin, Acc. Chem. Res., 2002, 35, 511-522.

7 S.-P. Zhao and X.-M. Ren, Dalton Trans., 2011, 40, 82618272 .

8 C. B. Aakeroy, A. M. Beatty, M. Nieuwenhuyzen and M. Zou, J. Mater. Chem., 1998, 8, 1385-1389.

9 R. Masse and J. Zyss, Mol. Eng., 1991, 1, 141-152.

10 G. R. Desiraju, Crystal engineering: The design of organic solids, Elsevier, 1989.

11 J. Zyss, R. Masse, M. Bagieu-Beucher and J. Levy, Adv. Mater., 1993, 5, $120-124$.

12 A. Facchetti, E. Annoni, L. Beverina, M. Morone, P. Zhu, T. J. Marks and G. A. Pagani, Nat. Mater., 2004, 3, 910-917.

13 C. C. Evans, M. Bagieu-Beucher, R. Masse and J. F. Nicoud, Chem. Mater., 1998, 10, 847-854.
14 M. Muthuraman, R. Masse, J. F. Nicoud and G. R. Desiraju, Chem. Mater., 2001, 13, 1473-1479.

15 J. P. Salvestrini, M. Abarkan, J. Zaccaro and A. Ibanez, J. Opt. Soc. Am. B, 2003, 20, 1661-1665.

16 H. O. Marcy, L. F. Warren, M. S. Webb, C. A. Ebbers, S. P. Velsko, G. C. Kennedy and G. C. Catella, Appl. Opt., 1992, 31, 5051-5060.

17 H. L. Bozec, T. L. Bouder, O. Maury, I. Ledoux and J. Zyss, J. Opt. A: Pure Appl. Opt., 2002, 4, S189-S196.

18 G. F. Lipscomb, A. F. Garito and R. S. Narang, J. Chem. Phys., 1981, 75, 1509-1516.

19 V. Ramamurthy and D. F. Eaton, Chem. Mater., 1994, 6, 1128-1136.

20 R. Hoss, O. Konig, V. Kramer-Hoss, U. Berger, P. Rogin and A. J. Hulliger, Angew. Chem., Int. Ed. Engl., 1996, 35, 1664-1666.

21 M. C. Etter, G. M. Frankenbach and D. A. Adsmond, Mol. Cryst. Liq. Cryst., 1990, 187, 25-39.

22 Y. Shi, C. Zhang, H. Zhang, J. H. Bechtel, L. R. Dalton, B. H. Robinson and W. H. Steier, Science, 2000, 288, 119-122.

23 J. Zyss, J. Phys. D: Appl. Phys., 1993, 26, B198-B207.

24 S. B. Monaco, L. E. Davis, S. P. Velsko, F. T. Wang, D. Eimerl and A. Zalkin, J. Cryst. Growth, 1987, 85, 252-255.

25 S. Haussuhl, H. A. Karapetyan, R. P. Sukiasyan and A. M. Petrosyan, Cryst. Growth. \& Des., 2006, 6(9), 2041-2046.

26 T. Pal, T. Kar, G. Bocelli and L. Rigi, Cryst. Growth Des., 2003, 3, $13-$ 16.

27 E. de Matos Gomes, E. Nogueira, I. Fernandes, M. Belsley, J. A. Paixao, A. Matos Beja, M. Ramos Silva, J. Martin-Gil and J. F. Mano, Acta Cryst., 2001, B57, 828-832.

28 T. Pal, T. Kar, X. Q. Wang, G. Y. Zhou, D. Wang, X. F. Cheng and Z. H. Yang, J. Cryst. Growth, 2002, 235, 523-528.

29 D. Xu, M. Jiang and Z. Tan, Acta Chim. Sin., 1983, 41, 570-573.

30 D. Eimerl, S. P. Velsko, L. E. Davis, F. T. Wang, G. Loiagono and G. Kennedy, IEEE J. Quantum Electron., 1989, 25, 179-193.

31 M. Szafranski, A. Katrusiak and G. J. McIntyre, Phys. Rev. Lett., 2002, 89, 215507-1-4.

32 G. M. Sheldrick, Acta Cryst., 2008, A64, 112-122.

33 A. L. Spek, J. Appl. Crystallogr., 2003, 36, 7-13.

34 D. J. McKee, J. F. H. Nicholls and I. S. Ruddock, Eur. J. Phys., 1995, 16, 127-134.

35 V. K. Dixit, S. Vanishri, H. L. Bhat, E. de Matos Gomes, M. Belsley, C. Santinha, G. Arunmozhi, V. Venkataramanan, F. Proenca and A. Criado, J. Cryst. Growth, 2003, 253, 460-466.

36 J. Jerphagnon and S. K. Kurtz, J. Appl. Phys., 1970, 41, 1667-1681.

37 F. H. Allen, Acta Cryst., 2002, B58, 380-388.

38 P. K. Ponnuswamy, A. V. Lakshminarayanan and V. Sasisekharan, Biochim. Biophys. Acta, Protein Struct., 1971, 229, 596-602.

39 C. K. Johnson, Oak Ridge National Laboratory Report, 1976, ORNL5138. 